\title{
Repeated exposure to organic material alters inflammatory and physiological
} airway responses

\author{
B-M. Sundblad, I. von Scheele, L. Palmberg, M. Olsson and K. Larsson
}

ABSTRACT: Farmers and smokers are repeatedly exposed to airborne organic material. We hypothesised that farmers and smokers show altered airway responses to inhaled organic, proinflammatory agents.

A total of 11 farmers, 12 smokers and 12 controls underwent lipopolysaccharide (LPS) bronchial challenge and spent $3 \mathrm{~h}$ in a pig barn. Lung function, exhaled nitric oxide and bronchial responsiveness were assessed and nasal lavage fluid and induced sputum were also collected. Symptoms and body temperature were recorded before and after exposures.

Following exposure to the pig barn, bronchial responsiveness, exhaled nitric oxide, sputum interleukin (IL)-6, nasal lavage cell count and IL-8 were increased to a greater extent in controls compared to farmers. The sputum IL-6 response was also attenuated in farmers after LPS challenge. The response shown by smokers following exposure to the pig barn was similar to that of controls regarding measurements of exhaled nitric oxide, IL-8 in nasal lavage and IL-6 in sputum, but more similar to farmers concerning bronchial responsiveness and the cell numbers present in nasal lavage. Sputum IL-8 showed a greater increase in smokers than in the other groups following LPS challenge.

We conclude that individuals who are repeatedly exposed to organic material develop an adaptation to the effects of acute exposure to inhaled organic material.

KEYWORDS: Bronchial responsiveness, inflammation, occupational exposure, pig barns, smoking

(D) ig farmers working in pig barns are exposed to organic material on a daily basis, which leads to chronic airway inflammation, even in those who do not experience airway symptoms [1]. Farmers also have higher prevalence of airway symptoms and chronic bronchitis than the general population $[2,3]$ and farmers run an increased risk of developing chronic obstructive pulmonary disease (COPD) [4]. It has been suggested that the acute inflammatory airway response that follows exposure to a pig barn is altered in pig farmers compared with healthy, previously unexposed control subjects [5, 6]. Previous results, therefore, have indicated that farmers develop an adaptation, which is most likely a consequence of repeated exposure to organic material in the pig barn environment [6-8]. In healthy subjects, acute exposure to a pig barn causes an intense airway inflammation, enhanced bronchial responsiveness and increased levels of exhaled nitric oxide [9-11]. Additionally, a near 100-fold increase in neutrophils, a three- to four-fold increase in lymphocytes and macrophages and a multifold increase in pro-inflammatory cytokine (interleukin (IL)-1, IL-6, IL-8 and tumour necrosis factor) levels have been demonstrated in bronchoalveolar lavage fluid (BAL) following exposure to pig confinement facilities [12,13]. Exposure to a pig barn also induces an intense inflammatory response in the upper airways, dominated by neutrophil granulocytes [11].

There are several microbial components of organic dust, including bacterial endotoxin (lipopolysaccharide (LPS)), that may contribute to the biological effects induced by exposure to a pig barn. However, it is not clear to what extent endotoxin contributes to the biological effects caused by exposure. Repeated exposure to endotoxin induces adaptation to further exposures by downregulating the inflammatory response [14]. Smokers are, like farmers, continuously exposed to organic compounds which also include endotoxin [15]. To our knowledge, there is no data regarding whether smokers, as a

\section{AFFILIATIONS}

Lung and Allergy Research, National Institute of Environmental Medicine, Karolinska Institutet, Stockholm,

Sweden.

CORRESPONDENCE

B-M. Sundblad

Lung and Allergy Research, National Institute of Environmental Medicine Karolinska institutet P0 Box 287

S-171 77 Stockholm

Sweden

E-mail: Britt-Marie.Sundblad@ki.se

\section{Received:}

July 112008

Accepted after revision:

Jan 042009

First published online:

Feb 122009 
consequence of repeated exposure to tobacco smoke, develop adaptation to further exposure to tobacco smoke or other organic material.

The present study was undertaken to find out whether the response to inhalation of organic dust and endotoxin is altered in individuals who are regularly exposed to organic material on a daily basis (pig farmers and smokers) compared to healthy nonsmokers. Our hypothesis was that tolerance has been developed in the continuously exposed groups and that there may be a cross reactivity between different types of exposure. Indicators of airway and systemic inflammatory responses and bronchial responsiveness were, therefore, assessed before and after exposure to a pig barn and bronchial LPS challenge (in random order) in pig farmers, smokers and nonsmoking, nonfarming healthy control subjects.

\section{METHODS}

\section{Subjects}

Subjects were recruited by advertisement in the daily press and working farmers were directly contacted by mail. A total of 36 subjects in three different groups $(n=12)$, i.e. controls, nonsmoking farmers and smokers, were included in the study. All subjects had normal lung function and had no airway hyperresponsiveness [16]. None had a history of COPD, asthma or allergy (confirmed with negative skin-prick tests to a panel of 12 common allergens) and had no other chronic diseases. None had suffered any respiratory tract infection during the 2 weeks prior to the study. Farmers were included if they had been exposed in the pig barn on a daily basis for the past 6 months, and smokers were included if they had smoked $\geqslant 10$ cigarettes per day during the year prior to the study. All subjects gave informed consent and the study was approved by the Ethics Committee of Karolinska Institutet (Stockholm, Sweden).

\section{Study design}

On two separate days, $\geqslant 3$ weeks apart, all subjects were exposed to dust in a pig barn and underwent a bronchial challenge with LPS in randomised order. On each occasion, 2-6 subjects from 2-3 groups were exposed in the pig barn while weighing pigs for $3 \mathrm{~h}$. Measurements of exposure levels were carried out at each occasion. Peak expiratory flow (PEF) was measured both before and 3, 4 and $5 \mathrm{~h}$ after the exposure.

On a separate day, six breaths of LPS were inhaled (Escherichia coli serotype 0111:B4 (Sigma-Aldrich Sweden AB, Stockholm) dissolved in $0.9 \%$ sterile saline, $1.25 \mathrm{mg} \cdot \mathrm{mL}^{-1}$ ), corresponding to $53.4 \mu \mathrm{g}$ LPS [17] using an inhalation dosimeter (SPIRA Elektro 2; Spira, Hameenlina, Finland). Forced expiratory volume in $1 \mathrm{~s}$ (FEV1) was measured before, and 30 and $60 \mathrm{~min}$ after, and then every hour for $6 \mathrm{~h}$ after the provocation.

Approximately 2 weeks before the first exposure and $7 \mathrm{~h}$ after the start of LPS and dust exposures, lung function and exhaled nitric oxide were measured, and a bronchial methacholine challenge and induced sputum performed. Nasal lavage was performed before and after dust exposure but not after LPS. Symptoms and body temperature were recorded before and up to $7 \mathrm{~h}$ after exposure.

\section{Symptoms}

General and airway specific symptoms were recorded before and after exposure on a visual analogue scale $0-100 \mathrm{~mm}$. The subjects were requested to put a cross on a scale where 0 indicated none, while 100 indicated unbearable symptoms.

\section{Lung function and bronchial responsiveness}

Vital capacity (VC) and FEV1 were measured before and $7 \mathrm{~h}$ after exposure using a wedge spirometer (Vitalograph, Buckingham, UK) according to American Thoracic Society (ATS) criteria [18]. Repeated FEV1 measurements after LPS challenge were measured with a One ${ }^{\circledR}$ Flow tester (Clement Clark Ltd, London, UK) and PEF was measured with a miniWright ${ }_{R}$ peak flow meter (Clement Clark Ltd). Local lung function reference values were used $[19,20]$.

Bronchial responsiveness to methacholine was tested as previously described [21]. Inhalation of the diluent was followed by inhalation of doubling concentrations of methacholine up to $32 \mathrm{mg} \cdot \mathrm{mL}^{-1}$ starting at $0.5 \mathrm{mg} \cdot \mathrm{mL}^{-1}$. The result was expressed as the cumulative dose causing a $20 \%$ decrease in FEV1 (PD20).

\section{Exhaled nitric oxide}

Nitric oxide in exhaled air was assessed using a single-breath exhalation with a flow rate of $50 \mathrm{~mL} \cdot \mathrm{s}^{-1}$, according to the ATS recommendations [22]. Exhaled nitric oxide was analysed by chemiluminescence after reaction with ozone $\left(\mathrm{NIOX}_{\mathbb{B}}\right.$; Aerocrine, Stockholm, Sweden). To decrease contamination from the oral cavity, mouthwash with water (30 s) and 10\% sodium bicarbonate $(30 \mathrm{~s})$ preceded the measurement procedure [23].

\section{Nasal lavage}

Nasal lavage was performed as previously described [24] with minor modifications [12]. Sterile $0.9 \% \mathrm{NaCl}(5 \mathrm{~mL})$ was instilled into one nostril and, $10 \mathrm{~s}$ later, expelled and collected. The procedure was repeated in the other nostril and the lavage samples were pooled. After centrifugation cell number was counted in a Bürker chamber. The supernatant was frozen $\left(-70^{\circ} \mathrm{C}\right)$ until further analysis.

\section{Sputum induction and processing}

Sputum induction and processing was performed as previously described [25] with minor modifications. After inhalation of salbutamol (0.4 mg), sputum was induced by inhalation of saline in increasing concentrations $(0.9 \%, 3.0 \%, 4.0 \%$ and $5.0 \%$ ), using an ultrasonic nebuliser (De Vibliss Ultraneb 2000; De Vibliss) with an output of $3 \mathrm{~mL} \cdot \mathrm{min}^{-1}$. Each concentration was inhaled for $7 \mathrm{~min}$ and followed by FEV1 measurement. Subjects were asked to blow their noses and rinse their mouths with water after each concentration, and then to cough deeply and to make an attempt to expectorate sputum. The sample was considered adequate when it macroscopically appeared to be free from saliva and had a weight of $\geqslant 1,000 \mathrm{mg}$.

Sputum colour and weight were determined and an equal volume of dithiothreitol $0.1 \%$ was added to the whole sputum sample and rocked for $15-25 \mathrm{~min}$ in a $37^{\circ} \mathrm{C}$ waterbath. The sample was centrifuged $(10 \mathrm{~min}$ at $280 \times g)$ and the supernatant stored in aliquots at $-70^{\circ} \mathrm{C}$ until analysis. 
The cell pellet was resuspended in $2 \mathrm{ml} \mathrm{PBS}$ and passed through a filter. Total cell count and viability test with Trypan blue was performed. Slides were prepared by cytocentrifuge and stained with May-Grünwald-Giemsa stain. A total of 300 cells were assessed for differential cell counts; $<100$ cells was considered too few for an accurate differential count. Sputum samples containing $>80 \%$ squamous cells were excluded from the analyses.

\section{Cytokine analysis}

IL-6 and IL-8 were measured in nasal lavage fluid and sputum using an in-house ELISA method. Commercially available antibody pairs (R\&D systems Europe, Abingdon, UK) were used as previously described [26]. The detection range for IL-6 and IL-8 was $2.8-375 \mathrm{pg} \cdot \mathrm{mL}^{-1}$ and $40-3,200 \mathrm{pg} \cdot \mathrm{mL}^{-1}$, respectively. For duplicate samples, an intra-assay coefficient of $<10 \%$ (nasal lavage) or $<15 \%$ (sputum) was accepted.

\section{Exposure measurements}

IOM filter cassettes (25 mm; SKC Ltd, Dorset, UK) and plastic cyclones (25 mm; Casella Ltd, London, UK) were used to monitor inhalable and respirable dust levels, respectively. The samplers were placed in the breathing zone on two subjects at each exposure occasion. The cassettes were equipped with Teflon filters $(1.0 \mu \mathrm{m}$; Millipore, Sundbyberg, Sweden). After weighing, the filter samplers were extracted and the endotoxin concentration was analysed using a kinetic technique version of Limulus amebocyte lysate assay (Limulus Amebocyte lysate, Endosafe ${ }_{\circledR}$ Endochrome-K ${ }^{\mathrm{TM}}$ U.S. Lisence No. 1197; Coatech AB, Kungsbacka, Sweden), with E. coli 0111:B4 as standard.

\section{Statistical analysis}

Within group comparisons were performed using ANOVA repeated measurements, followed by paired t-test (lung function, $\log$ PD20) or Friedman's test, followed by Wilcoxon signed rank-sum test as post hoc test. Between-group comparisons in bronchial responsiveness were logarithmically transformed and analysed by means of ANOVA with Fisher's protected least significant difference as post hoc test. Other between-group comparisons were analysed by the KruksalWallis test using the Mann-Whitney U-test as a post hoc test, when appropriate. A value of $\mathrm{p}<0.05$ was considered significant. The results were analysed using StatView version 5.0.1 (SAS Institute Inc., Cary, NC, USA).

\section{RESULTS}

\section{Subjects}

In total, 12 nonsmoking pig farmers, 12 smokers with no respiratory symptoms (according to a questionnaire) and 12 nonsmoking, nonfarming controls participated in the study (table 1). One farmer was pregnant at the first visit and therefore excluded from further participation. Another farmer experienced a migraine headache $5 \mathrm{~h}$ after the LPS challenge and was not included in the analyses of the LPS provocations.

The pig farmers had worked as farmers for mean (range) 13 (0.5-36) yrs, spending $3.5(0.5-8) \mathrm{h}$ per day in pig barns containing $1,000(60-3,200)$ pigs. The cumulative smoking exposure in the smoking group was 21 (1.5-48) pack-yrs.

\section{Symptoms and body temperature}

LPS provocation induced headache and fatigue in all three groups $(p \leqslant 0.007)$ with no significant differences between the groups.

\section{TABLE 1 Baseline (pre-exposure) characteristics of the three groups}

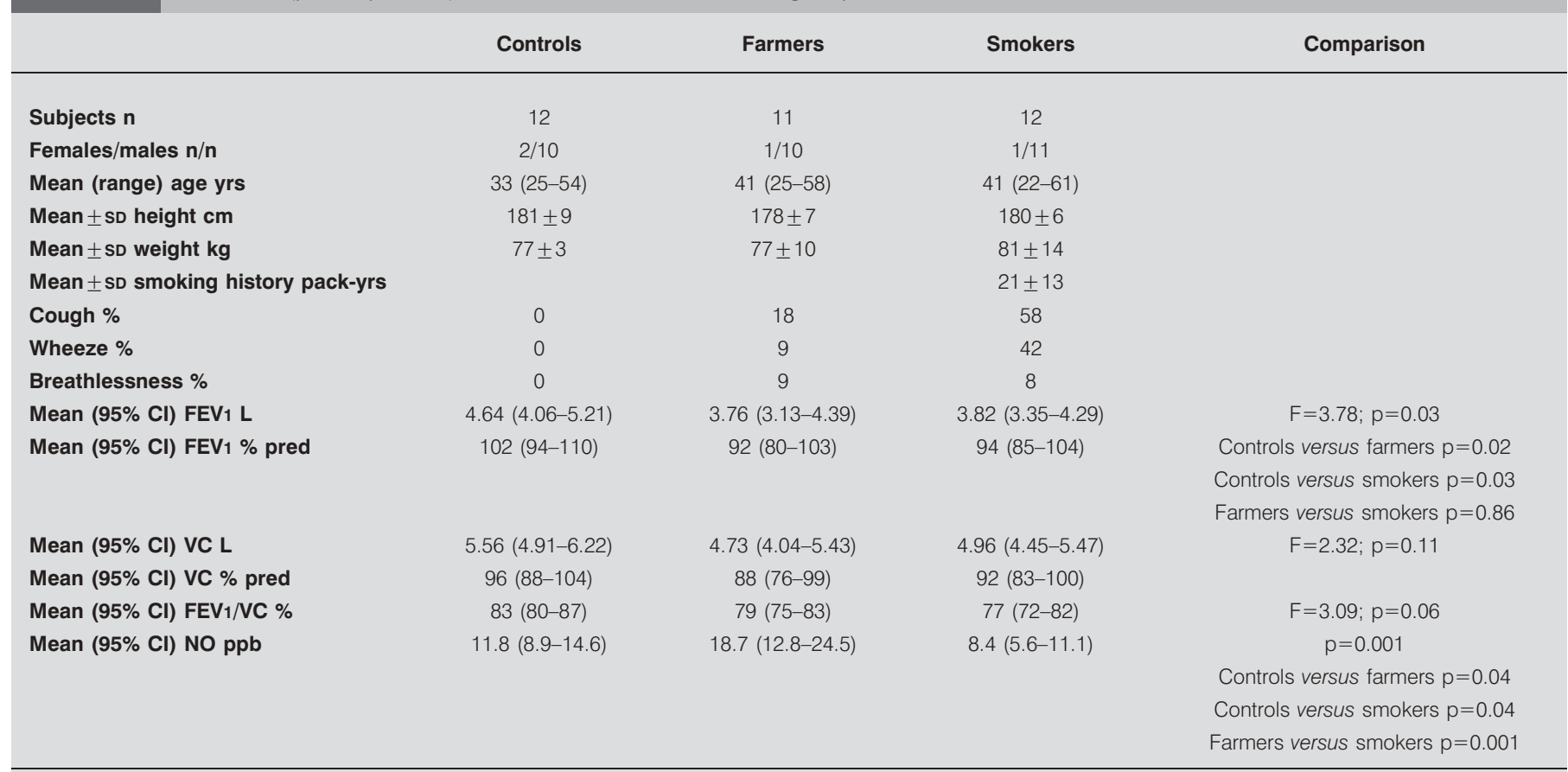


TABLE 2 Changes in lung function in healthy nonsmoking, nonfarming controls, smokers and farmers

\begin{tabular}{|c|c|c|c|c|c|c|c|c|}
\hline & Mean $(95 \% \mathrm{Cl})$ & $\mathrm{p}$-value & Mean $(95 \% \mathrm{Cl})$ & $p$-value & Mean $(95 \% \mathrm{Cl})$ & $\mathrm{p}$-value & Mean $(95 \% \mathrm{Cl})$ & p-value \\
\hline Controls & $-0.12(-0.21--0.04)$ & 0.008 & $-0.22(-0.32--0.13)$ & 0.0004 & $-0.10(-0.18--0.02)$ & 0.02 & $-0.26(-0.35--0.17)$ & $<0.0001$ \\
\hline Farmers & $-0.01(-0.13-0.10)$ & 0.8 & $-0.10(-0.17--0.03)$ & 0.01 & $-0.05(-0.18-0.08)$ & 0.4 & $-0.14(-0.26--0.03)$ & 0.02 \\
\hline Smokers & $-0.09(-0.23-0.05)$ & 0.2 & $-0.21(-0.39--0.03)$ & 0.02 & $0.02(-0.11-0.15)$ & 0.8 & $-0.12(-0.25-0.003)$ & 0.06 \\
\hline
\end{tabular}

Differences $(\Delta)$ between pre-exposure and $7 \mathrm{~h}$ after lipopolysaccharide (LPS) challenge and exposure in a pig barn. The influence of LPS and pig barn exposure did not differ significantly between the three groups. Cl: confidence interval; VC: vital capacity; FEV1: forced expiratory volume in $1 \mathrm{~s}$.

Exposure in the pig barn induced chills, runny nose, cough and chest tightness in the controls, cough in the smokers and chest tightness in the farmers. Dust exposure induced more cough in controls $(p=0.04)$ and smokers $(p=0.002)$ than in farmers.

The mean increase in body temperature was $0.43^{\circ} \mathrm{C}$ after LPS $(n=34)$ and $0.61^{\circ} \mathrm{C}$ after pig house exposure $(n=35)$. Temperature increased significantly in controls $(\mathrm{p}=0.001)$ and smokers $(p=0.03)$ following LPS challenge and after dust exposure in all groups $(p \leqslant 0.01)$, with no significant differences between the groups after either stimulus.

\section{Lung function and bronchial responsiveness}

Baseline FEV1 measurements were significantly lower in farmers and smokers than in controls (table 1). A small decrease in VC and FEV1 was observed after LPS and dust exposure in controls and after exposure to dust in smokers and farmers (table 2).

Following LPS challenge, a maximal decrease in FEV1 was observed at $3 \mathrm{~h}(\mathrm{p}<0.001)$ with no differences between the groups. VC and FEV1 were reduced only in the controls $7 \mathrm{~h}$ after LPS challenge. Additionally, dust exposure induced a slight reduction in FEV1 $(p \leqslant 0.033)$ with no significant differences between the groups (table 2).

After dust exposure PEF fell in controls $(p<0.0001)$ and smokers $(p=0.003)$ but not in farmers $(p=0.19)$, and to a lesser extent in farmers than in the other groups $(\mathrm{F}=4.38 ; \mathrm{p}=0.021)$.

Pre-exposure bronchial responsiveness did not differ significantly between the groups (fig. 1). LPS induced an increase in bronchial responsiveness which did not differ between the groups $(\mathrm{F}=0.02 ; \mathrm{p}=0.98)$. Bronchial responsiveness increased after dust exposure to a greater extent in controls than in farmers $(p<0.001)$ and smokers $(p<0.001)$, with no difference observed between farmers and smokers $(p=0.57$; fig. 1$)$. The absolute level of PD20 was similar in all groups after dust exposure $(F=0.26 ; p=0.77)$.

\section{Exhaled nitric oxide}

Pre-exposure levels of exhaled nitric oxide were lower in smokers than in the other groups and higher in farmers than in controls and smokers (fig. 2, table 1).

LPS inhalation did not influence exhaled nitric oxide levels, whereas dust exposure significantly increased the exhaled nitric oxide levels in controls and smokers, but not in farmers (fig. 2); the levels were significantly less in farmers than in the other groups $(p=0.007)$.

There was a negative correlation between the increase in exhaled nitric oxide following dust exposure and the cumulative exposure to tobacco smoke $(r=-0.54 ; \mathrm{p}=0.05)$.

\section{Nasal lavage}

Pre-exposure cell number and cytokine (IL-6 and IL-8) levels in nasal lavage fluid were similar in the three groups $(\mathrm{p} \geqslant 0.28$; fig. 3). Following exposure, IL-8 in nasal lavage increased to a lesser extent in farmers than in the other groups $(p=0.007)$, and nasal lavage cell count increased significantly more in controls $(p=0.003$; fig. 3$)$. The IL-6 alteration in nasal lavage fluid after dust exposure did not differ between the groups $(p=0.30)$.

\section{Sputum}

Pre-exposure IL-6 in sputum was higher in smokers than in controls $(p=0.001)$. Smokers exhibited the highest sputum IL-6-levels following LPS challenge, whereas farmers showed a lower increase in sputum IL-6 levels than the other groups following dust exposure (fig. 4).

Pre-exposure IL-8 in sputum was higher in smokers and farmers than in controls $(p=0.01)$, and LPS induced a greater sputum IL-8 in smokers compared to the other groups $(p=0.03$; fig. 4). Sputum IL-8 increased more in smokers than in farmers following dust exposure $(p=0.02)$.

Pre-exposure sputum cell count was similar in the three groups (fig. 4) and LPS exposure induced a smaller increase in farmers than in the other groups $(p=0.04)$. Dust exposure induced similar changes in cell number in the three groups $(\mathrm{p}=0.28$; table 3$)$.

\section{Exposure measurements}

The median (interquartile range) levels of inhalable and respirable dust were $8.3(6.2-9.7) \mathrm{mg} \cdot \mathrm{m}^{-3}$ and $0.32(0.30-$ $0.33) \mathrm{mg} \cdot \mathrm{m}^{-3}$, respectively. The corresponding endotoxin concentrations were $62.8(48.0-85.3) \mathrm{ng} \cdot \mathrm{m}^{-3}$ and 12.9 (3.026.9) $\mathrm{ng} \cdot \mathrm{m}^{-3}$.

The airborne levels of hydrogen sulphide were below the detection limit $(<0.05 \mathrm{ppm})$ on all exposure occasions and the ammonia concentration was $5.0(3.0-6.6)$ ppm $(n=7)$. 


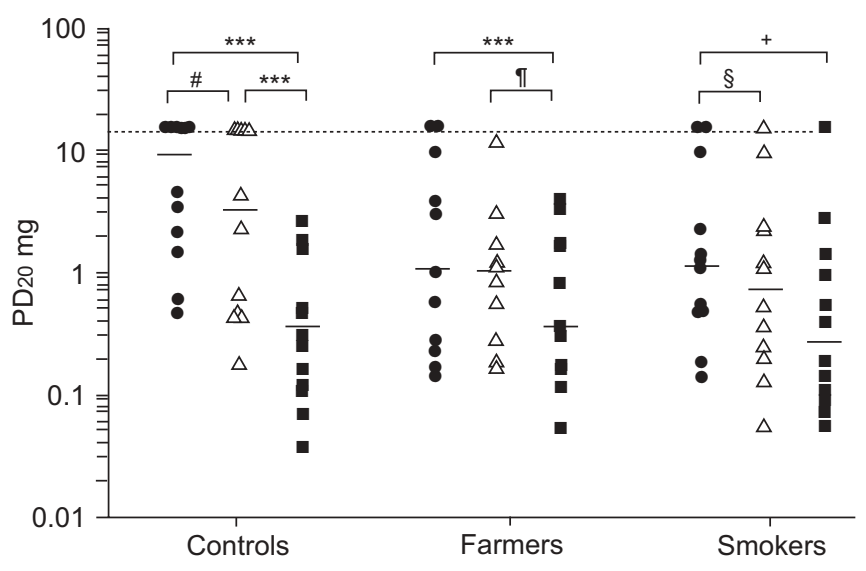

FIGURE 1. Bronchial responsiveness to methacholine (as measured by the cumulative dose causing a 20\% decrease in forced expiratory volume in $1 \mathrm{~s}$ (PD20)) at baseline $(\bullet)$, after lipopolysaccharide (LPS) challenge $(\triangle)$ and after exposure in the pig barn ( $\mathbf{\square})$. Horizontal lines indicate medians; $p$-values for within-group (preto post-exposure) differences are as follows. ${ }^{\#}: p=0.01 ;{ }^{\circ}: p=0.02 ;{ }^{+}: p=0.003$; s: $p=0.04 ;{ }^{* * *}: p<0.001$. Pre-exposure PD20 did not differ between the groups ( $F=2.60 ; p=0.09$, ANOVA; $p=0.073$, Kruskal-Wallis test). There was no significant difference between the groups with regard to the reaction to $L P S(F=0.02 ; p=0.98)$. Exposure in the pig barn induced a significantly greater enhancement of bronchial methacholine responsiveness in the controls compared with farmers and smokers $(p<0.001)$.

\section{DISCUSSION}

In the present study it was demonstrated that both symptomfree smokers and farmers, two groups of individuals who are repeatedly exposed to organic material on a daily basis, have signs of an ongoing airway inflammation in the lower, but not in the upper, airways. The most noticeable finding was the different response to exposure in a pig barn between the groups. In general, farmers responded to a lesser extent than controls, whereas smokers responded similarly to controls with regard to certain parameters, but more like farmers regarding others. Exposure-induced symptoms, physiological outcomes (lung function and bronchial responsiveness) and markers of airway inflammation (exhaled nitric oxide, and cells and cytokines in sputum and nasal lavage fluid) were attenuated in farmers compared with controls. Our results thus indicate an adaptation to acute exposure in farmers that is also observed to a certain extent in smokers. Another clear finding was that exposure to dust in the pig barn was a much stronger pro-inflammatory stimulus than the inhalation of pure endotoxin (LPS), even though the doses of the latter are more than 200-fold (see below) higher than the doses inhaled in pig barns. Inhalation of LPS induced similar alterations in lung function and bronchial responsiveness in the three groups. However, the response, as assessed by sputum cell content and IL-6 levels, was downregulated in farmers compared with smokers and controls, whereas the IL-8 response was augmented in smokers.

Pig barn exposure induced less of an increase in bronchial responsiveness in smokers and farmers than in controls, the increase in controls being similar to that previously shown [10]. The present results are in line with previous findings of an attenuated response in farmers [5] and show that smokers

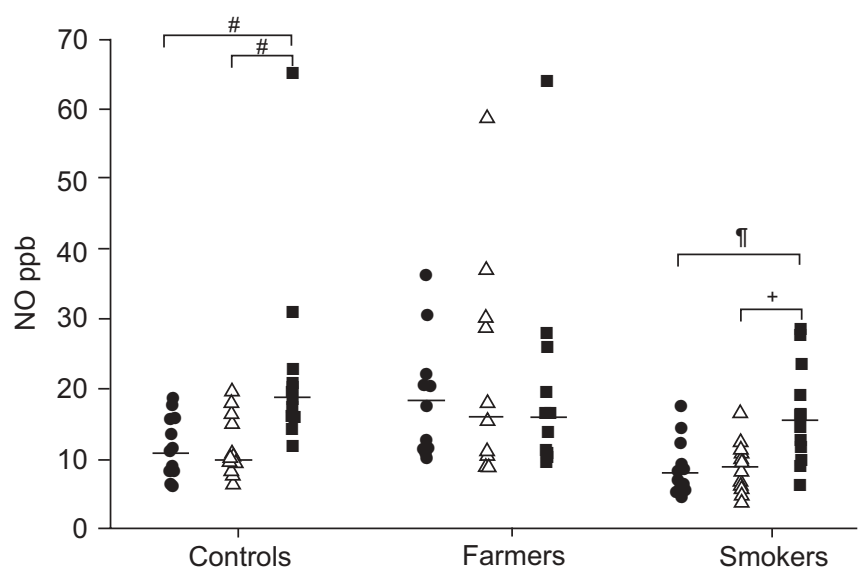

FIGURE 2. Exhaled nitric oxide at baseline $(\mathbf{0})$ and following lipopolysaccharide $($ LPS) $(\triangle)$ and pig barn ( $\mathbf{\square})$ exposure. Horizontal lines indicate medians; p-values for within-group (pre- to post-exposure) differences are as follows. ${ }^{\#}: p=0.002$; $\because \mathrm{p}=0.005 ;^{+}: \mathrm{p}=0.004$. LPS did not influence exhaled nitric oxide levels in either group $(F=1.11 ; p=0.34)$. Exhaled nitric oxide increased more in controls $(p=0.003)$ and smokers $(p=0.02)$ than in farmers after pig barn exposure.

seem to be more similar to farmers than to controls in these respects. Regarding the increased bronchial responsiveness following exposure in the pig barn, we cannot exclude the possibility that this difference was influenced by the small, although nonsignificant, difference in pre-exposure bronchial responsiveness. We have previously shown that the interindividual difference in the absolute, post-dust PD20 value is small, implicating that the exposure-induced increase in bronchial responsiveness is almost totally independent of pre-exposure values [27]. Absolute post-dust PD20 was similar in the three groups, indicating that the exposure-induced enhancement may be due to the nonsignificant differences in the pre-exposure values.

For most of the outcome measures, exposure in a pig barn was a stronger stimulus than was inhalation of pure LPS. Interestingly, we found no differences between the groups with regard to the enhancement of bronchial responsiveness following LPS challenge, but bronchial responsiveness increased to a greater extent in the controls than in the other groups after dust exposure. This indicates that exposure in a pig barn induces a maximal increase in bronchial responsiveness (PD20 was similar in all three groups after dust exposure), whereas exposure to endotoxin does not. It has also been shown that mice with defective Toll-like receptor 4 (TLR4; an important receptor for LPS) have an attenuated inflammatory response in the lung after exposure in a swine stable, but there was no effect on bronchial responsiveness compared with wild-type mice [28].

Assuming a ventilation rate of $15-20 \mathrm{~L} \cdot \mathrm{min}^{-1}$ during the light work carried out in the pig barn, the total ventilation during $3 \mathrm{~h}$ would be $\sim 3 \mathrm{~m}^{3}$, leading to a total endotoxin exposure of $<200 \mathrm{ng}\left(\sim 63 \mathrm{ng} \cdot \mathrm{m}^{-3}\right)$, which should be compared with the exposure of $53.4 \mu \mathrm{g}$ LPS during the LPS challenge. Furthermore, inhalation of LPS did not influence the level of exhaled nitric oxide in either group, while dust exposure 

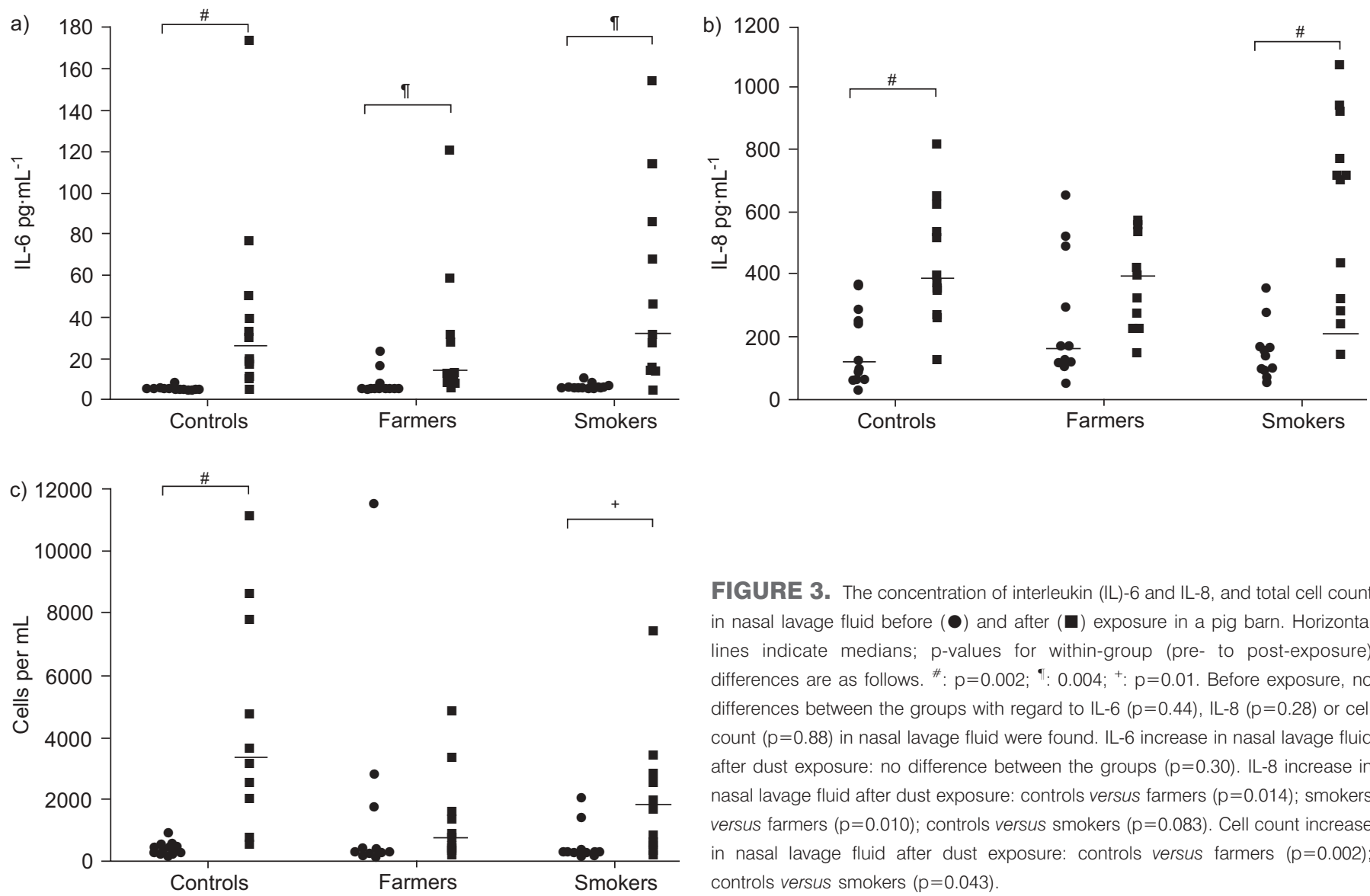

FIGURE 3. The concentration of interleukin (IL)-6 and IL-8, and total cell count in nasal lavage fluid before $(\bullet)$ and after $(\boldsymbol{\square})$ exposure in a pig barn. Horizontal lines indicate medians; $p$-values for within-group (pre- to post-exposure) differences are as follows. ${ }^{*}: p=0.002 ;{ }^{\top}: 0.004 ;{ }^{+}: p=0.01$. Before exposure, no differences between the groups with regard to IL-6 $(p=0.44), I L-8(p=0.28)$ or cell count $(p=0.88)$ in nasal lavage fluid were found. IL-6 increase in nasal lavage fluid after dust exposure: no difference between the groups $(p=0.30)$. IL-8 increase in nasal lavage fluid after dust exposure: controls versus farmers $(p=0.014)$; smokers versus farmers $(p=0.010)$; controls versus smokers $(p=0.083)$. Cell count increase in nasal lavage fluid after dust exposure: controls versus farmers $(p=0.002)$; controls versus smokers $(p=0.043)$.

increased exhaled NO-levels in controls and smokers but not in farmers. In addition, the cell and cytokine (IL-6 and IL-8) response assessed in sputum was generally stronger after exposure to dust than LPS. The differences between LPS and dust exposure are intriguing considering that the endotoxin dose after LPS challenge is more than 200 times higher than the total endotoxin exposure during $3 \mathrm{~h}$ of work in a pig barn. These findings strongly support the idea that endotoxin is not the most important pro-inflammatory constituent of organic dust from pig barns. Previous results indicate that microbial products from Gram-positive bacteria may be of importance for the biological reaction to exposure in a pig barn [29, 30]. From these data it may also be concluded that the attenuated response observed in farmers and to some extent in smokers, is not due to endotoxin tolerance.

The pre-exposure exhaled nitric oxide levels were higher in farmers than in controls, which may be due to daily exposure to microbial products in the farming environment [31]. We confirmed previous findings of low levels of exhaled nitric oxide in smokers, in whom downregulation of nitric oxide synthase has been demonstrated [32]. Exhaled nitric oxide was unaffected after LPS exposure in all three groups. This is in conflict with earlier findings of elevated exhaled nitric oxide following LPS exposure in a study similar to ours [33]. Exposure in the pig barn induced increased exhaled nitric oxide levels in controls and smokers, but not in farmers. The difference in post-exposure increases in nitric oxide levels may be explained by the different pre-exposure levels, as the absolute post-exposure nitric oxide levels are similar in the three groups.

The farmers exhibited an attenuated cell and cytokine response after pig barn exposure compared with smokers and controls, as assessed in nasal lavage fluid and sputum. These exposureinduced differences cannot be explained by different preexposure values, which were similar in the three groups. Chronic exposure in the farming environment includes exposure to high amounts of bacteria and microbial products, an exposure which, in the long term, may influence the inflammatory response to irritating stimuli, and pathogenassociated molecular patterns (PAMP). It has been shown that smokers exhibit downregulation of TLR2 on alveolar macrophages, a receptor that binds PAMP [34], and we have recently demonstrated reduced expression of TLR-2 on blood monocytes in farmers [35]. It cannot be excluded that this downregulation of TLR2 expression is related to the attenuated inflammatory response [34, 35].

Cigarette smoke contains high levels of endotoxin and it has been demonstrated that smoking one cigarette results in the inhalation of $17.4 \mathrm{pmol}$ of endotoxin and that indoor exposure to environmental tobacco smoke leads to the inhalation of $12.1 \mathrm{pmol}$ of LPS $\cdot \mathrm{m}^{-3}$ [15]. LAAN et al. [36] showed that cigarette smoke extract inhibited LPS-induced production and mRNA expression of granulocyte macrophage colony-stimulating 


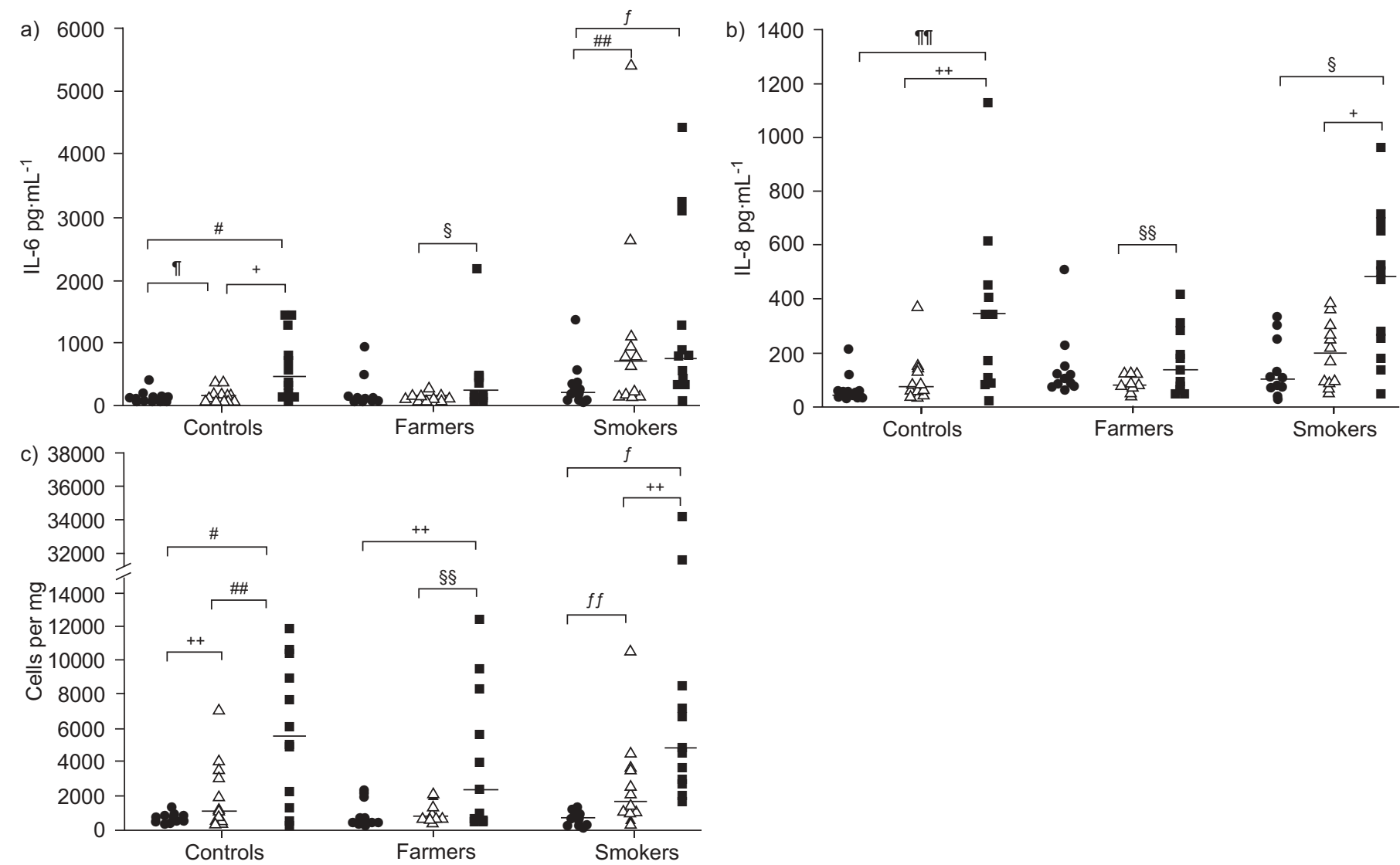

FIGURE 4. The concentration of interleukin (IL)-6 and IL-8, and total cell count in sputum before $(\bullet)$ and $7 \mathrm{~h}$ after lipopolysaccharide (LPS) challenge ( $\triangle$ ) and exposure

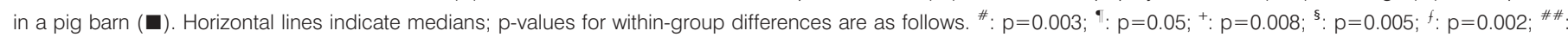
$p=0.02 ;{ }^{\top 9}: p=0.006 ;{ }^{++}: p=0.01 ;{ }^{\xi \xi}: p=0.03 ;{ }^{f f}: p=0.004$. IL-6 differences before exposure: controls versus smokers $(p=0.001)$. IL-8 differences before exposure: controls versus farmers ( $p=0.007)$; controls versus smokers $(p=0.015)$. Cell count differences before exposure: no difference between the groups $(p=0.76)$. IL-6 increases after LPS challenge: controls versus farmers ( $p=0.010)$; controls versus smokers $(p=0.05)$ and smokers versus farmers $(p=0.002)$. IL-8 increases after LPS challenge: smokers versus controls ( $p=0.013)$; smokers versus farmers $(p=0.018)$. Total cell number increases after LPS challenge: controls versus farmers $(p=0.047)$; smokers versus farmers $(p=0.019)$. IL-6 increases after dust exposure: controls versus farmers $(p=0.049)$; smokers versus farmers $(p=0.016)$. IL-8 increases after dust exposure: smokers versus farmers $(p=0.023)$. Total cell count increases after dust exposure: no difference $(p=0.92)$.

factor and IL-8 in human bronchial epithelial cells. Their data indicated that cigarette smoke possesses immunosuppressive properties in the airways by downregulating the pathogeninduced production of neutrophil-mobilising cytokines. We therefore hypothesised that adaptation to acute exposure to organic dust occurs in smokers as well as in farmers. We found a negative correlation between exhaled nitric oxide following dust exposure and smoking habits, possibly indicating an attenuated

TABLE 3 Cell differential counts and squamous cell content in induced sputum samples in healthy nonsmoking, nonfarming controls, smokers and farmers before and $7 \mathrm{~h}$ after exposure in a pig barn and a lipopolysaccharide (LPS) challenge

\begin{tabular}{|c|c|c|c|c|c|c|c|c|c|}
\hline & \multicolumn{3}{|c|}{ Controls } & \multicolumn{3}{|c|}{ Farmers } & \multicolumn{3}{|c|}{ Smokers } \\
\hline & Pre-exposure & Post-LPS & Post-dust & Pre-exposure & Post-LPS & Post-dust & Pre-exposure & Post-LPS & Post-dust \\
\hline Subjects $\mathbf{n}$ & 11 & 10 & 12 & 9 & 7 & 10 & 11 & 12 & 12 \\
\hline Macrophages \% & $91.5(77.6-93.4)$ & $42.5(33.5-50)$ & $6.5(4.5-12.8)$ & $62.8(29-88.5)$ & 30 (18-62.2) & $7.5(4.8-12-8)$ & $43(24.6-63.5)$ & $18.2(7.5-42.2)$ & $4.2(2.8-5.8)$ \\
\hline Neutrophils \% & $5.5(4.1-16.4)$ & $52.2(47.5-59.5)$ & $90.5(84.5-94.5)$ & $36.5(8-67.5)$ & 67 (33.9-81.2) & $87.5(83.8-92.5)$ & $52(33.7-74.2)$ & $75.2(52.8-88.2)$ & $94.5(92.5-95.8)$ \\
\hline Lymphocytes \% & $3(1.6-5.4)$ & $3(2-5.5)$ & $2(1.2-4)$ & $2.2(0.5-3.2)$ & $2.5(0.1-3.5)$ & $2(1-4.9)$ & $1.5(0.2-2.9)$ & $4(1.8-7)$ & $1.5(0.8-1.8)$ \\
\hline $\begin{array}{l}\text { Squamous } \\
\text { cells } \%\end{array}$ & $25(12.2-33)$ & $12.5(3-20)$ & $4(1.5-8.5)$ & $13(7.8-26)$ & $25(10.2-29.8)$ & $12.5(3-21)$ & $11(6.8-16.8)$ & $10.5(4.5-23.5)$ & $5(2-10.5)$ \\
\hline
\end{tabular}

Values are given as median (interquartile range), unless otherwise stated. No eosinophils were observed in the sputum samples 
response in the most heavy smokers. Conversely, the sputum IL-6 and IL-8 response to LPS exposure was stronger in smokers than in controls and farmers, which is in line with the finding of a more pronounced increase in peripheral blood neutrophils after LPS provocation in smokers compared with controls and farmers (K. Sahlander and co-workers, Institute of Environmental Medicine, Karolinska Institutet, Stockholm, Sweden; personal communication). There are thus factors which support the idea that smokers may respond more strongly to LPS exposure than nonsmokers, thereby contradicting the hypothesis of LPS adaptation in smokers. These observations are supported by the finding by Wesselius et al. [37], who showed that the recovery of neutrophils and IL- $1 \beta$ concentration in BAL fluid from smokers exceeded that of nonsmokers after LPS inhalation.

In conclusion, we have demonstrated that clinical, physiological and inflammatory airway responses to acute pro-inflammatory agents are attenuated in farmers and (to some extent) smokers compared with controls. It is suggested that the adaptation, clearly identified in farmers, is a result of longterm daily exposure to organic material. However, exposure to the farming environment and tobacco smoke do not activate identical adaptive mechanisms. The results strongly indicate that endotoxin is not the most important pro-inflammatory agent in organic dust in a pig barn. It is unclear whether the adaptation to exposure, with downregulation of inflammatory responses, is a significant factor in the increased prevalence of chronic bronchitis and COPD observed in farmers and smokers.

\section{SUPPORT STATEMENT}

This study was supported by grants from the Swedish Heart and Lung Foundation (Stockholm, Sweden), the National Institute of Environmental Medicine (Karolinska Institutet, Stockholm), the Research Department of AFA Insurance Company (Stockholm) and the Swedish Farmer Foundation for Agricultural Research (Stockholm).

\section{STATEMENT OF INTEREST}

A statement of interest for this study can be found at www.erj. ersjournals.com $/ \mathrm{misc} /$ statements.dtl

\section{ACKNOWLEDGEMENTS}

The authors wish to thank F. Acevedo, K. Sahlander and A. Ek (Institute of Environmental Medicine, Karolinska Institutet, Stockholm, Sweden) for excellent technical assistance. We also wish to thank K. Strandberg (Institute of Environmental Medicine, Karolinska Institutet) for the physical examination of the volunteers.

\section{REFERENCES}

1 Larsson K, Eklund A, Malmberg $\mathrm{P}$, et al. Alterations in bronchoalveolar lavage fluid but not in lung function and bronchial responsiveness in swine confinement workers. Chest 1992; 101: 767-774.

2 Vogelzang P. Health-based selection for asthma, but not for chronic bronchitis, in pig farmers: an evidence-based hypothesis. Eur Respir J 1999; 13: 187-189.

3 Zejda JE, Hurst TS, Barber EM, et al. Respiratory health status in swine producers using respiratory protective devices. Am J Ind Med 1993; 23: 743-750.

4 Monso E, Riu E, Radon K, et al. Chronic obstructive pulmonary disease in never-smoking animal farmers working inside confinement buildings. Am J Ind Med 2004; 46: 357-362.
5 Palmberg L, Larsson B-M, Malmberg P, et al. Airway responses of healthy farmers and nonfarmers to exposure in a swine confinement building. Scand J Work Environ Health 2002; 28: 256-263.

6 Von Essen S, Romberger D. The respiratory inflammatory response to the swine confinement building environment: the adaptation to respiratory exposures in the chronically exposed worker. J Agric Saf Health 2003; 9: 185-196.

7 Hoffmann HJ, Iversen M, Sigsgaard T, et al. A single exposure to organic dust of non-naive non-exposed volunteers induces longlasting symptoms of endotoxin tolerance. Int Arch Allergy Immunol 2005; 138: 121-126.

8 Poole JA, Wyatt TA, Von Essen SG, et al. Repeat organic dust exposure-induced monocyte inflammation is associated with protein kinase C activity. J Allergy Clin Immunol 2007; 120: 366-373.

9 Larsson K, Eklund A, Hansson LO, et al. Swine dust causes intense airways inflammation in healthy subjects. Am J Respir Crit Care Med 1994; 150: 973-977.

10 Malmberg P, Larsson K. Acute exposure to swine dust causes bronchial hyperresponsiveness in healthy subjects. Eur Respir J 1993; 6: 400-404.

11 Sundblad B-M, Larsson B-M, Palmberg L, et al. Exhaled nitric oxide and bronchial responsiveness in healthy subjects exposed to organic dust. Eur Respir J 2002; 20: 426-431.

12 Larsson B-M, Palmberg L, Malmberg PO, et al. Effect of exposure to swine dust on levels of IL-8 in airway lavage fluid. Thorax 1997; 52: 638-642.

13 Wang Z, Larsson K, Palmberg L, et al. Inhalation of swine dust induces cytokine release in the upper and lower airways. Eur Respir J 1997; 10: 381-387.

14 West MA, Heagy W. Endotoxin tolerance: a review. Crit Care Med 2002; 30: Suppl., S64-S73.

15 Larsson L, Szponar B, Pehrson C. Tobacco smoking increases dramatically air concentrations of endotoxin. Indoor Air 2004; 14: 421-424.

16 Ehrs PO, Sundblad BM, Larsson K. Quality of life and inflammatory markers in mild asthma. Chest 2006; 129: 624-631.

17 Thorn J. The inflammatory response in humans after inhalation of bacterial endotoxin: a review. Inflamm Res 2001; 50: 524-261.

18 American Thoracic Society. Standardization of spirometry, 1994 update. Am J Respir Crit Care Med 1995; 152: 1107-1136.

19 Hedenström H, Malmberg P, Fridriksson HV. Reference values for pulmonary function tests in men: regression equations which include tobacco smoking variables. Upsala J Med Sci 1986; 91: 299-310.

20 Hedenström H, Malmberg P, Agarwal K. Reference values for lung function tests in females: regression equations with smoking variables. Bull Eur Physiopathol Respir 1985; 21: 551-557.

21 Malmberg P, Larsson K, Thunberg S. Increased lung deposition and biological effect of methacholine by use of drying device for bronchial provocation tests. Eur Respir J 1991; 4: 890-898.

22 American Thoracic Society. Recommendations for standardized procedures for the online and offline measurement of exhaled lower respiratory nitric oxide and nasal nitric oxide in adults and children - 1999. Am J Respir Crit Care Med 1999; 160: 2104-2117.

23 Zetterquist W, Pedroletti C, Lundberg JON, et al. Salivary contribution to exhaled nitric oxide. Eur Respir J 1999; 13: 327-333.

24 Bascom R, Pipkorn U, Lichtenstein L, et al. The influx of inflammatory cells into nasal washings during the late respose to antigen challenge. Am Rev Respir 1988; 138: 406-412.

25 in 't Veen JC, de Gouw HW, Smits HH, et al. Repeatability of cellular and soluble markers of inflammation in induced sputum from patients with asthma. Eur Respir J 1996; 9: 2441-2447.

26 Larsson K, Tornling G, Gavhed D, et al. Inhalation of cold air increases the number of inflammatory cells in the lungs in healthy subjects. Eur Respir J 1998; 12: 825-830.

27 Strandberg K, Ek A, Palmberg L, et al. Fluticasone and ibuprofen do not add to the effect of salmeterol on organic dust-induced 
airway inflammation and bronchial hyper-responsiveness. J Intern Med 2008; 264: 83-94.

28 Charavaryamath C, Juneau V, Suri SS, et al. Role of Toll-like receptor 4 in lung inflammation following exposure to swine barn air. Exp Lung Res 2008; 34: 19-35.

29 Wang Z, Malmberg P, Larsson B-M, et al. Exposure to bacteria in swine-house dust and acute inflammatory reactions in humans. Am J Respir Crit Care Med 1996; 154: 1261-1266.

30 Larsson B-M, Larsson K, Malmberg P, et al. Gram positive bacteria induce IL-6 and IL-8 production in human alveolar macrophages and epithelial cells. Inflammation 1999; 23: 217-230.

31 Donham KJ, Popendorf W, Palmgren U, et al. Characterization of dusts collected from swine confinement buildings. Am J Ind Med 1986; 10: 294-297.

32 Kharitonov S, Robbins R, Yates D, et al. Acute and chronic effects of cigarette smoking on exhaled nitric oxide. Am J Respir Crit Care Med 1995; 152: 609-612.
33 Rolla G, Bucca C, Brussino L, et al. Pentoxifylline attenuates LPSinduced bronchial hyperresponsiveness but not the increase in exhaled nitric oxide. Clin Exp Allergy 1997; 27: 96-103.

34 Droemann D, Goldmann T, Tiedje T, et al. Toll-like receptor 2 expression is decreased on alveolar macrophages in cigarette smokers and COPD patients. Respir Res 2005; 6: 68.

35 Sahlander K, Larsson K, Palmberg L. Altered expression of inflammatory markers in blood in pig farmers. Eur Respir J 2005; 26: Suppl. 49, 584s.

36 Laan M, Bozinovski S, Anderson GP. Cigarette smoke inhibits lipopolysaccharide-induced production of inflammatory cytokines by suppressing the activation of activator protein- 1 in bronchial epithelial cells. J Immunol 2004; 173: 4164-4170.

37 Wesselius LJ, Nelson ME, Bailey $\mathrm{K}$, et al. Rapid lung cytokine accumulation and neutrophil recruitment after lipopolysaccharide inhalation by cigarette smokers and nonsmokers. J Lab Clin Med 1997; 129: 106-114. 